\title{
УПРАВЛЕНИЕ ФОНДОМ НАЦИОНАЛЬНОГО БЛАГОСОСТОЯНИЯ В УСЛОВИЯХ КОРОНАКРИЗИСА
}

\author{
(c) 2020 Зельднер Алексей Григорьевич \\ доктор экономических наук, профессор, главный научный сотрудник \\ Институт экономики РАН, Россия, Москва \\ Email: tzeldner@gmail.com
}

В статье подробно рассматриваются возможности использования Фонда национального благосостояния в условиях пандемии коронавируса и падения спроса и цен на продукцию ТЭК. ФНБ рассматривается как источник стабильности национальной экономики и как источник возможности инновационного развития и структурной модернизации российской экономики.

Ключевые слова: макроэкономика, инновации, бюджетное правило, Фонд национального благосостояния, управление.

Россия - ведущая страна в мире по добыче топливных ресурсов, страна занимала второе место в мире по добыче природного и попутного газа и третье место в мире по нефти, включая газовый конденсат [1]. Топливно-энергетический комплекс России в условиях сырьевой модели развития страны играет важнейшую роль в экономике России. По данным за 2019 г., ТЭК обеспечил 25\% ВВП страны; формировал почти 40\% федерального бюджета и четверть всех инвестиций России[2]. За счет сверхдоходов, в основном полученных от реализации продукции ТЭК, удалось нарастить ФНБ до современных размеров (свыше 12,8 трлн. руб.), позволяющих создать подушку безопасности и возможность оказать существенную поддержку предприятиям и населению в коронакризисный период.

K началу 2020 г. ситуация на мировых рынках нефти резко поменялась. Пандемия, вызвавшая мировой коронавирусный кризис, параллельно с ненахождением консенсуса странами ОПЕК по объему добычи и продажи нефти привели к резкому падению спроса на нефть (и продукты ее переработки и снижению цен). По сути, бюджет лишился значительной части своих доходов. Учитывая зависимость нашей страны от реализации сырьевых ресурсов, правительство заблаговременно стало формировать резервные фонды.

В современном виде ФНБ функционирует с 2018 г. (хотя был сформирован в 2008 г.). Произошло это вследствие объединения ФНБ и Резерв- ного фонда, который с 1.02 .2018 г. прекратил свою деятельность. В результате объединения к функциям ФНБ - софинансирования пенсионных накоплений с целью сбалансированности бюджета Пенсионного фонда - добавилась и функция по покрытию дефицита федерального бюджета. Объем ФНБ на начало апреля 2020 г. превысил 12,8 трлн. рублей или 165,4 млрд. долларов (по соответствующему курсу), это 12,3\% ВВП России. Такой объем Фонда при рациональном его использовании может поддержать страну на протяжении ряда лет.

Формирование ФНБ осуществляется за счет резервирования сверхдоходов выше базовой цены на нефть (42,4 долл. за барр. в ценах 2020 г. с ежегодной индексацией на $2 \%$ ), с одной стороны, это подушка безопасности в случае наступления кризиса, (что и произошло в 2020 г. из-за пандемии коронавируса). Но существует и обратная сторона - необходимо развивать экономику, диверсифицировать ее с тем, чтобы при падении спроса на сырьевые ресурсы страна могла выйти на мировой рынок не только с зерном и оружием, но и с товарами инновационного плана. Стране, претендующей на мировое лидерство, необходимо инвестировать в приоритетные проекты, обеспечивающие развитие высокотехнологического сектора, инфраструктурные и импортозамещающие проекты. В противном случае нам долго еще придется излечиваться от «голландской болезни»* .

Становление в России сырьевой модели

\footnotetext{
* «Голландская болезнь» означает наиболее конкурентные условия для ведущей отрасли в ущерб других. Более того, длительность этого состояния, как это видно на примере России, приводит к структурным изменениям и деиндустриализации. В России проявилось и специфическое отличие от общих тенденций мирового опыта - она сохранила современные технологии в военно-промышленном комплексе, потеряв темп и качество модернизации и индустриального развития несырьевых отраслей промышленности.
} 
привело к тому, что перспективы ее развития в значительной мере зависят от конъюнктуры мировых цен на нефть. Этот рукотворный тренд развития, известный под названием «голландская болезнь», был заложен в России почти тридцать лет назад и с упорством, достойным лучшего применения, и продолжает реализовываться.

В статье «Как справиться с голландской болезнью вопреки ресурсному проклятию» бразильский экономист Л.Броссер-Перейда пишет: «Есть простой способ проводить политику, не обращаясь к тарифным мерам и субсидиям... Надо установить переменный налог на экспорт товара, порождающего «болезнь», размер которого зависит от того, насколько завышен реальный курс. Последнее, в свою очередь, зависит в основном от колебаний цен на мировом рынке. Если цена растет, то и налог повышается, и наоборот» [3].

В 2017 г. было принято «бюджетное правило», согласно которому «из ФНБ нельзя тратить больше суммы недополученных доходов от реализации нефти ниже базовой цены». Вот этот момент и требует, по мнению многих, изменения, что в итоге позволит использовать большие суммы из ФНБ для поддержки экономики и населения, в частности, в чрезвычайных ситуациях. Спустя год в России приняты поправки к бюджетному правилу, позволяющие все нефтегазовые доходы, полученные выше цены отсечения, использовать Минфином для приобретения валюты и размещения ее в ФНБ.

В соответствии с бюджетным правилом, нефтегазовые доходы при цене нефти выше базовой цены (цены отсечения) направляются в ФНБ. Если же цена отсечения ниже базовой валюта из фонда продается для компенсации потерь. В целом выпадающие нефтегазовые доходы компенсируются из ФНБ, а ненефтегазовые - за счет займов. По данным министра финансов А. Силуанова, власти собираются дополнительно занять для компенсации ненефтегазовых доходов от 1,5 до 2\% ВВП [4].

Бюджетное правило имеет макроэкономическую направленность, концентрируясь на проблемах макроэкономической устойчивости. Вот почему оно находит широкое применение в странах мира. «Если в начале 1990-х годов только семь стран использовали инструмент бюджетного правила при проведении налоговобюджетной политики, то в 2015 г. таких стран насчитывалось 85» [5].
«Бюджетное правило - механизм, снижающий зависимость федерального бюджета от цен на энергоносители. То, что оно применяется в России большой плюс для экономики. Но вопрос состоит в том, насколько это правило эффективно при изменении макроэкономических условий» [6]. Следует отметить, что предложение экономистов о повышении цены отсечения в условиях, когда цена на нефть превышала ее примерно в два раза (77 долл./барр. в 2018 г.), имела основание. Дело в том, что возрастающая разница между ценой отсечения и экспортной ценой на нефть оказывала давление, во-первых, на национальную валюту, а, во-вторых, влияла на рост затрат в отраслях экономики, работающих на производство потребительских товаров.

Катастрофическое падение спроса и цены на нефть в 2020 г. в силу ряда причин обострила проблему пополнения бюджета и ФНБ и его использования. Встает вопрос об изменении подходов к бюджетному правилу, вызывающему различные мнения. Так, по мнению председателя ЦБ Э.Набиуллиной, финансовая стабильность российской экономики обеспечивается бюджетным правилом в совокупности с мерами денежно-кредитной политики. «Содержание и суть бюджетного правила нельзя менять, в том числе цену отсечения (сейчас 42,4 долл. за баррель)» [4].

Министр финансов А.Силуанов высказал свое мнение в отношении цены отсечения: «Она каждый год растет на 2\%, в 2022 г. будет уже 44 доллара за баррель, по нынешним временам это очень высокая планка» [4]. В ходе парламентских слушаний по основным направлениям бюджетной и налоговой политики в 2019-2021 годах глава Счетной палаты РФ А.Кудрин заявил: «Бюджетное правило, которое сегодня базируется на 40 долларах за баррель нефти, можно сделать мягче - 45 долларов за баррель. Но тогда нам бы не пришлось бы сейчас повышать НДС» [7]. Повышение цены отсечения в период высоких цен на нефть позволило бы увеличить вложения в стимулирование экономики, в инфраструктуру, инновационное развитее, модернизацию несырьевой экономики. «Бюджетное правило - это инструмент кастрирования российской экономики, считает В. Жуковский, член президиума Столыпинского клуба. Бюджетное правило - это инструмент, который не допускает роста экономики и роста инвестиций, промышленного производства и уровня жизни на- 
селения. Что такое бюджетное правило? Это, по большому счету, даже не сырьевая игла, а сырьевой кол, на который посажена вся Россия и все население страны. Сколько бы ни стоила сегодня нефть на сырьевых рынках - 60 долларов за бочку, 80 долларов или 100 долларов - мы все равно по этому бюджетному правилу будем жить, как при нефти по 40 долларов за баррель» [7].

Но ситуация на нефтяном рынке с начала 2020 г. резко меняется. Цена на нефть марки Brend c февраля по апрель снизилась в три раза. В России из-за падения цен и спроса бюджет в марте потерял 22 млрд. руб., в апреле в два с лишним раза больше, в мае ожидается продолжение понижательного тренда. Следует также учитывать сезонный фактор (помимо пандемии коронавируса), в летний период традиционно падает потребление энергоресурсов. По прогнозам Международного энергетического агентства (МЭА), спрос на нефть по итогам 2020 г. снизится на $9 \%$, на газ - на $5 \%$ [8].

В сложившейся ситуации необходимо менять бюджетное правило, использовать возможности ФНБ для стимулирования структурных изменений, развития инновационной экономики и инфраструктурное обустройство страны. Бюджетное правило ограничивает использование накопленных резервов в ФНБ для поддержания и стимулирования роста экономики. Согласно бюджетному правилу, уже с апреля 2020 г. Минфин начинает покупать валюту, так как цена отсечения ниже 42,4 долл./барр., полученные денежные средства используются для возмещения выпадающих нефтяных доходов, позволяя восстановить статус-кво, но не наращивать бюджетные расходы. Учитывая снижение цен и спроса, следует ожидать и снижения ненефтегазовых доходов (за счет НДС и налога на прибыль), но их компенсация также невозможна из ФНБ изза бюджетного правила. «При общих ожидаемых выпадающих доходах бюджета в 2020 г. в 3-4 трлн. руб. (при ценах на нефть 25-35 долл./барр.) ожидаемый дефицит удастся закрыть продажами валют из ФНБ по бюджетному правилу только на 1,1-1,7 трлн. руб., остальное придется покрывать увеличением заимствований» [9]. И это при том, что к снижению цен и спроса на нефть из-за пандемии, ФНБ подошел, имея свыше 12 трлн. руб., но выделить большую сумму на антикризисные меры, чем 1,4 трлн. руб. мешает бюджетное правило. Бюджетное правило ограничивает суммы расходов как ненефтегазовых, так и нефтегазовых (по цене отсечения). При этом выпадающие доходы в первом случае компенсируются займами, а нефтегазовые - за счет средств ФНБ. Снятие (частично) ограничений бюджетного правила позволило бы не только повлиять на колебание нефтяных цен, но сглаживать колебания экономики.

Для реализации полномасштабной антикризисной программы необходим комплекс дополнительных мер, который должен включать: дальнейшее снижение ключевой ставки ЦБ, расширение кредитования и наращивание госдолга, а ситуация с низкой госзадолженностью позволяет ЦБ это осуществить, причем, учитывая, что происходит замещение доходов, не отражающееся на росте инфляции. На пресс-конференции в мае 2020 г. председатель Банка России Э.Набиуллина заявила, что госдолг страны находится на низком по сравнению с другими странами уровня $12,4 \%$ ВВП, а совместно с региональным - 13,8\% ВВП. Доля ОФЗ в балансе банков $4 \%$. Следует отметить, что в стране принимаются определенные меры по наращиванию расходов сверх того, то позволяет бюджетное правило. Так, получено разрешение на расходование средств от продажи акций Сбербанка на сумму примерно 1,5 трлн. руб., а также на ненефтегазовые доходы.

Пока на борьбу с коронавирусно-нефтяным кризисом правительство России выделяет 1,4 трлн. руб. Это около 1,3\% ВВП, в то же время налогово-бюджетные стимулы Чехии на борьбу с пандемией составили $2 \%$ ВВП, Казахстана $-3,4 \%$ ВВП, Японии - 4,9\% ВВП, Канады - 6\% ВВП, Австралии - 9,7\% ВВП, США - 10,5\% ВВП. В соответствии с Бюджетным кодексом расходы текущего года могут быть увеличены за счет ненефтегазовых доходов (это могут быть налоги, поступления от приватизации и доходы от управления средствами ФНБ). Но практика показывает, что этого недостаточно. Глава Счетной палаты А. Кудрин предположил, что «экономике понадобится пакет госпомощи величиной от 5\% ВВП, то есть порядка 5,5 трлн. руб.» [9].

Вводимые антикризисные пакеты мер правительством России ограничиваются не выделением конкретных средств, а в основном введением налоговых отсрочек, снижением страховых взносов для малого бизнеса, но это все за счет сокращения доходов внебюджетных фондов, а не федерального бюджета. Минфин не собирается сокращать общие расходы бюджета, 
но будет проведена «приоритизация расходов, то есть их перераспределение от менее приоритетных к более приоритетным».

Активизируя денежно-кредитную политику, Банк России снизил до 5,5\% ключевую ставку и планирует дальнейшее снижение. Складывается впечатление, что меняются и его приоритеты главное экономика, а не таргетирование инфляции. «Более того, в России начнется собственный вариант политики «количественного смягчения» в виде долгосрочных операций РЕПО. Первые операции годового РЕПО должны начаться в конце июня. В качестве обеспечения выступят ОФЗ, таким образом будет стимулирован спрос банков на госдолг и повысится уровень ликвидности в банковской системе. Даже анонс появления этого инструмента способствовал росту спроса на новые выпуски ОФЗ» [10].

В плане активизации использования государственных фондов различных стран представляет интерес опыт Норвегии. Норвегия - крупнейший экспортер нефти и газа. Отрасль находится под госконтролем, обеспечивая половину товарного экспорта и треть бюджетных доходов. В 1990 г. в Норвегии был создан государственный нефтяной фонд для обеспечения нужд будущих поколений. В 2006 г. он был преобразован в государственный пенсионный фонд с сохранением ранее установленных функций. Доходы фонда формируются из прибыли, получаемой от реализации нефти и газа за счет: налогов на добывающие компании, продажу лицензий на поиски углеводородов, поступлений от участия в капитале добывающих компаний. Фонд Норвегии активно размещает часть средств фонда в более широкий круг активов, инвестируя в корпоративные акции и облигации, что существенно отличает его от консервативной инвестиционной стратегии ФНБ, ориентированной на вложения в максимально надежные активы, прежде всего суверенные облигации*. Необходимо расширить возможность размещения средств ФНБ в более широкий круг активов. Это может способствовать повышению доходности вложений ФНБ. Так среднегодовая доходность ФНБ в последние годы составляла около 1,5\% против 5,9\% в год в среднем с 1998 года в случае фонда Норвегии [11].

В условиях планетарного коронанефтяного кризиса многие страны отходят от строгих бюджетных правил ради преодоления последствий кризиса и стимулирования социальноэкономических процессов. И в этом направлении следует работать на опережение, а не опаздывать, как это произошло с прямыми разовыми выплатами населению с детьми от 3 до 16 лет. Выход из кризиса связан не только с восстановлением цен на углеводороды, но с потребительским спросом населения, а это десятки миллионов людей, потерявших работу из-за разорения малого и среднего бизнеса и оптимизации рабочих мест в промышленных предприятиях. В этой связи необходимо пересмотреть и размер пособий по безработице, которые должны составить не менее двух третей средней заработной платы, сложившейся в стране на взрослого и минимум по 10 тыс. руб. на каждого неработающего члена семьи. В этих условиях в стране вырастет спрос населения - важнейший стимул для развития производства.

В заключение отметим следующее:

1. Объем ФНБ в России позволяет оказывать максимальную поддержку предприятиям, включая малый и средний бизнес и населению, у которого и до коронакризиса снижались в течение пяти лет реальные доходы. В апреле 2020 г. резко обострился коронавирусный кризис, что привело к существенному снижению доходов федерального бюджета до 1,2-1,3 трлн. руб., в то время как расходы возросли до 2,3 трлн. руб. [12]. Расходы коснулись помощи здравоохранению, региональным и муниципальным бюджетам, социальным и другим объектам. Сравнение с зарубежными странами по поддержке производства и населения в условиях кризиса говорит об очень скромных расходах российского правительства, несмотря на солидные запасы ФНБ. Распечатка ФНБ требует мужества и реальной ответственности за свой народ и за будущее экономики.

Необходимо существенно расширить и возможности использования ФНБ, для чего целесообразно пересмотреть бюджетное правило, учитывая коронакризисную ситуацию, с которой современный мир столкнулся впервые. За расходование средств ФНБ на преодоление кризиса, в частности, выступал глава Счетной палаты Алексей Кудрин. «Потом можно больше занимать на рынках и тем самым помогать бюджету, но в этом году острота кризиса такова, что нужно по-

\footnotetext{
* Суверенная облигация (гособлигация) - долговая ценная бумага, эмитированная с целью покрытия бюджетного дефицита от имени правительства и гарантированная правительством. Суверенные облигации могут деноминироваться как в национальной, так и мировой резервной валюте.
} 
больше потратить из фонда»,- утверждал глава Счетной палаты, предлагая потратить около половины средств ФНБ [13].

2. Снижение спроса и цен, сокращение производства и экспорта нефти и газа оказывает существенное влияние на доходную часть бюджета*, что в небольшой части может, при прочих равных условиях, компенсироваться ростом курса доллара. По оценке экономической экспертной группы, недобор нефтегазовых доходов может достигнуть 5,5 трлн. руб., часть из которых, согласно бюджетному правилу, должна была бы пополнить ФНБ. Но, согласно бюджетному правилу, примерно 60\% недобора этого дохода должна была бы быть направлена в ФНБ, что уменьшает сумму для пополнения. По Бюджетному кодексу разница между фактическими и расчетными доходами должна покрываться из ФНБ. Для этого ЦБ ежемесячно покупает валюту для Минфина на дополнительные доходы от продажи нефти сверх базовой цены $(42,4$ долл. за баррель), которая направляется в ФНБ. Учитывая падение нефтегазовых доходов, как от снижения спроса, так и снижения цены, сокращение поступлений налогов, компенсация выпадающих доходов возможна за счет расширения госзаимствования и выкупа выпускаемых облигаций федерального займа (ОФЗ), которые ЦБ выпускает, по сути, «финансируя правительство за счет эмиссии» [14].

3. Известный английский публицист У.Бэджет в книге «Ломбард-стрит» сформулировал знаменитое правило о поведении центрального банка в условиях кризиса, которое актуально звучит и в условиях коронавирусного кризиса: «Для поддержания долгосрочной стабильности во время кризиса и паники центральные банки должны быть готовы предоставить банкам займы - 1) без ограничений, 2) под высокий процент и 3) только под залог высококачественных активов» [15].

На протяжении XX века правило Бэджета считалось аксиомой. Но коронавирусный кризис заставляет центральные банки запустить экстренные меры поддержки, как банковского сектора, так и экономики в целом, и многие из этих мер вынужденно противоречат золотому прави- лу Бэджета. Так ФРС США объявил о «предоставлении ликвидности финансовым организациям под залог рискованных активов». Не остался в стороне и Центральный банк России. «Репо, которые регулярно проводит Банк России, по сути, также является примером нарушения правила Бэджета, так как кредитные риски залогов, принимаемые на баланс ЦБ, сложно оценить» [15].

Как известно, ЦБ планирует предоставить банкам «рефинансирование через операции репо на срок в один год и один месяц. Приниматься будет ограниченный список бумаг, в первую очередь, ОФЗ» [16]. Только одно намерение ЦБ об использовании ОФЗ привели к тому, что 20.05.2020 Минфин продал облигации федерального займа на 170 млрд. руб. Это абсолютный рекорд дневных продаж [17].

4. Мир вместе с Россией переживает коронавирусный кризис, который рано или поздно закончится, но страны сырьевой зависимости ожидает уже в недалеком будущем новый нефтяной кризис, связанный с быстрорастущими инновационными разработками по использованию возобновляемых источников энергии.

«На данный момент самый перспективный источник энергии - это водород и топливный элемент, который вырабатывает электроэнергию, сжигая водород. Японская автомобильная компания Тойота», например, разрабатывает новую машину с таким топливным элементом в США, к проекту присоединились также Royal Dutch Shell и некоторые другие компании. А в Германии и Франции уже начались испытания экспериментальных поездов на новых топливных элементах... Если будет найден экономически эффективный способ получения водорода путем электролиза морской воды с использованием солнечной энергии, то прорыв в новую энергетику станет необратимым: страны, зависящие от добычи ископаемого топлива, сами окажутся в положении ископаемых - но уже бесполезных... Что из этого следует? Со всей очевидностью только одно: России надо устанавливать новую государственную модель, которая не зависит от углеродов. За границей пригодного для копирования образца нет - придется искать самим. И делать это нужно быстро...» [18].

\footnotetext{
* Если бы ЦБ не перечислил в бюджет деньги от продажи пакета акций Сбербанка (более 1 трлн. руб.), бюджет января-апреля 2020 г. был бы закрыт с дефицитом примерно 3\% ВВП [19].
} 


\section{Библиографический список}

1. Россия в цифрах 2019. Росстат. М. 2019. С. 548.

2. Российская газета 30.04.2020.

3. Bresser-Pereira L.C. How to neutralize the Dutch disease notwithstanding the natural resources curse. FGV Sao Paulo School of Economics Working Paper, 2017, no. 452 Available at: http://www. bresser-pereira.org. br/ papers/2017/305-TD452.pdf

4. https://www.vedomosti.ru/economics/articles/2020/05/08/829856-elvira-nabiulina?utm_source=google \&utm medium=news \&utm_campaign=top-n...

5. Швандар К., Черкасов В., Бурова Т. Голландская болезнь: применение бюджетного правила и роль структурных реформ. Финансовый журнал. 2017. № 5. С. 23

6. Кукушкин К. Во имя рубля. Почему бюджетное правило надо менять. https://www.forbes.ru/fmansv-iinvesticii/368501-vo-imya-rublva-pochemu-byudzhetnoe-pravilo-nado-menyat

7. https://regnum.ru/news/economy/2599727.html

8. https://aif.ru/money/kuda_neft_tuda_i_gaz_podesheveet_li_goluboe_toplivo_glya_rossiyan

9. https://www.rbc.ru/economics/08/04/2020/5e8b541b9a79470d40d7264b

10. https://www.rbc.ru/opinions/finances/14/05/2020/5ebbfda29a79470af04d20cb

11. https://e-markets.nordea.com/\#!/article/53027/stoit-li-tratit-fond-natsional-nogo-blagosostoyaniya

12. Шелин C. Почему Россию так внезапно «вернули к нормальной жизни» https:/www.rosbalt.ru/ blogs/2020/05/19/1844203.html?utm_sourse=rosbalt \&utm_medium=web\&utm_campaign=editorchoice

13. https://www.rbc.ru/economics/19/05/2020/5ec36c889a7947dcf7394036?from=newsfeed

14. Гурвич E. Нефтяной стресс-тест: 20 долларов за баррель. Российская газета 24.04.2020.

15. https://www.vedomosti.ru/economics/blogs/2020/05/18/830425-tsentralnie-banki

16. Гайдаев В. В госдолге увидели залог будущего. Коммерсант 14.05.2020.

17. https://www.vedomosti.ru/finance/articles/2020/05/20/830680-rubl-podderzhal-rekordnii-spros-na-gosdolg

18. Кавато А. Конец нефтяной эры? Японский взгляд на будущее энергетики. Ж. Огонек. № 19 от 18.05.2020. С. 21. https://www.kommersant.ru/doc/4341811

19. Вислогузов В. Бюджет переходит на минус. Коммерсант. 18.05.2020 